Original Research Paper

\title{
Comparison of Air Quality in Kuwait Urban and Industrial Areas
}

\author{
${ }^{1}$ Hamad B Matar, ${ }^{1}$ Talal Almutairi and ${ }^{2}$ Nayef Z. Al-Mutairi \\ ${ }^{1}$ Department of Civil Engineering, College of Technological Studies (PAAET), Kuwait \\ ${ }^{2}$ Department of Civil Engineering, College of Engineering and Petroleum, Kuwait University, Kuwait
}

\author{
Article history \\ Received: 13-12-2019 \\ Revised: 24-02-2020 \\ Accepted: 06-04-2020 \\ Corresponding Author: \\ Hamad B Matar \\ Department of Civil \\ Engineering, College of \\ Technological Studies \\ (PAAET), Kuwait \\ Email: hb.matar@paaet.edu.kw
}

\begin{abstract}
This paper describes the research carried out to investigate air quality in Kuwait. It examined the results of several years of pollutants data provided by Kuwait Environment Public Authority. The data were obtained from a number of fix monitoring stations. The results of the time series analysis have shown that monitored exposures vary substantially and are unique to the location and temporal variation of the measured site (background, urban area, industry area and refinery area). Also, outdoor pollutant levels were governed more by the characteristics of traffic rather than level of flow and traffic.
\end{abstract}

Keywords: Air Pollution, $\mathrm{SO}_{2}, \mathrm{CO}, \mathrm{NO}, \mathrm{O}_{3}$ and $\mathrm{PM}_{10}$

\section{Introduction}

Air pollution defined as the introduction of gaseous substances to the air by human that hazard to well-being or health, or yield additional detrimental ecological effects (EPA, 2006). The particles and gaseous are the types of air pollution emission, which are classified into primary and secondary pollutants. The emission of pollutant directly into the air is called primary pollutants. The reaction of emission in atmosphere is called secondary pollutants. The use of oil and coal has caused smog in some major cities since the 1930s, such as Los Angeles in the 1940s and London in 1952 (Vallero, 2008). Air pollution issues have been identified and addressed by researchers and legislators since then. The interdiction of the air quality concept and standards were introduced in the 1970s. In 1987, the first personal exposure guidelines was published for ambient Particulates (PM), nitrogen dioxide $\left(\mathrm{NO}_{2}\right)$, Ozone $\left(\mathrm{O}_{3}\right)$ and sulphur dioxide $\left(\mathrm{SO}_{2}\right)$ by the World Health Organization (WHO, 1987). The personal exposure allowed was reduce in subsequent guidelines by more than $50 \%$ due to studies which showed observable health effects studies on (WHO, 1987). The change in the guidelines was supported by epidemiological studies of mortality (Anderson, 2009). High personal exposure to $\mathrm{O}_{3}$ and $\mathrm{PM}$ have been associated with respiratory and cardiovascular illness (Dockery et al., 1993; Pope et al., 1995; Abbey et al., 1999; Bell et al., 2004; U.S.EPA, 2006; Lin et al., 2008; Yang and Omaye, 2008). The Kuwait Environment Public Authority (KU-EPA) published new standards and guidelines for outdoor pollutant levels in 2017.
The main source of air pollution are road transport and Industry. Depending on the location, the personal exposure and pollutants emissions may vary greatly. Zhang and Batterman (2013) stated that road transportation, especially vehicles, has become the key cause of air contaminants in metropolitan areas in the USA. Murena and Favale (2007) stated that meteorological conditions, site topography and traffic conditions have an effect on the outdoor emissions levels. The duration and severity of road traffic congestion increased pollutant emissions and lowered air quality, especially near large highways. In Kuwait, the accumulation of air pollutants was caused by power plants, desalination plants, refineries and petrochemical plants and road traffic; with a steady growth in population and vehicles $3.4 \%$ and 9\% respectively (EFDBB, 2004; MIK, 2019). Al-Temeemi (1995) stated that air quality is effected by road transportation emissions and an increase in fuel consumption.

There is much research on air pollution in Kuwait. Abdul-Wahab, 2009 reported that $\mathrm{NO}_{2}$ level surpassed the current ambient air quality standards in Khaldiya, Kuwait by $26.9 \%$. At three air quality monitoring stations, the monthly concentrations of $\mathrm{NOx}$ and $\mathrm{SO}_{2}$ were higher than air quality standards (Al-Mutairi and Koushki, 2009). Another paper stated that $\mathrm{SO}_{2}$ levels exceeded the daily limit in several locations in Kuwait (Al-Rashidi et al., 2005). Al-Awadhi (2014) reported lower pollutant levels compare to KU-EPA standards by using passive sampling in Kuwait residential areas. Al-Khulaifi et al. (2014) conducted studies on various seasonal pollutants in Kuwait. 


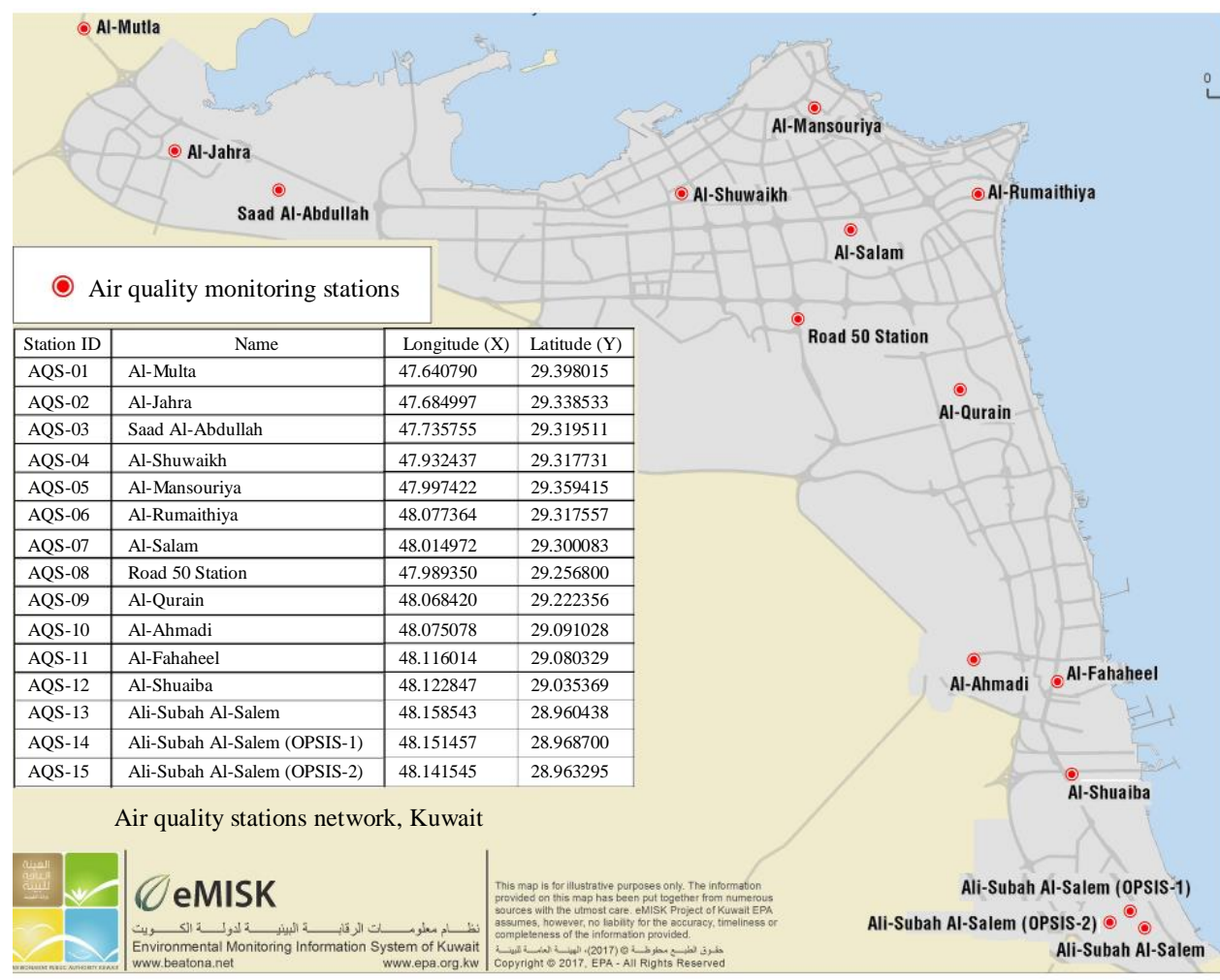

Fig. 1: Kuwait AQMS location

Kuwait Environment Public Authority set up a number of fix of monitor stations, as shown in Fig. 1 to measured pollutant levels. Precise stationary AQMS monitors were installed in Kuwait urban, industrial, oil field and background areas to monitor air pollution levels. The objective of this paper is to examine air pollution in metropolitan Kuwait as related to road traffic and other sources by selecting AQMS in urban, industrial and refinery areas and background. The data from three AQMS for the dates from 1/1/2012 until 31/12/2017 were obtained to represent background (Al-Mutla), urban areas (Al-Shuwaikh, Al-Salam, Al-Fahaheel Ali-Subah AlSalem, Ali-Subah Al-Salem (OPSIS-1) and Ali-Subah AlSalem (OPSIS-2)) and industrial area (Al-Shuaiba). However, there is some overlap in classification in these areas. Though designated urban, the Al-Shuwaikh, Road 50 Station Urban, Ali-Subah Al-Salem, Ali-Subah AlSalem (OPSIS-1) and Ali-Subah Al-Salem (OPSIS-2) were located near an industrial area and Al-Fahaheel was located near a refinery.

\section{Methodology}

\section{Study Area}

In this paper, the data was collected in Kuwait. Kuwait EPA has 15 monitor stations, as shown in Fig. 1. These stationary precision monitors have been installed in background, urban and industrial areas. Nine stationary precision monitors have been selected to represent the background and residential areas as shown in Fig. 1. The AQMA station located at Al-Mutla represents background pollutant levels and the other eight represent refinery, industrial, refinery and residential area pollutants levels.

\section{Data}

The hourly pollutants levels, $\mathrm{SO}_{2}, \mathrm{CO}, \mathrm{NO}, \mathrm{O}_{3}$ and $\mathrm{PM}_{10}$, data was obtained from Kuwait EPA for six years (1/1/2012-31/12/2017). There were missing data ranges from several hours to months. The data was obtained for Kuwait City only. The data were transferred into the Microsoft Excel format and amalgamated into a master spread-sheet using the time as a benchmarking variable. These data were analyzed using Excel, SPSS and R (openair) software packages to carry out descriptive analysis.

\section{Results}

Six years of $\mathrm{SO}_{2}, \mathrm{CO}, \mathrm{NO}, \mathrm{O}_{3}$ and $\mathrm{PM}_{10}$ hourly concentration were collected. There were some missing periods in the data provided. First, the time series data for the pollutants were plotted for a better understanding of the temporal and spatial variation of measured pollution. Figure 2 to 6 represents all the data, the daily 
Hamad B Matar et al. / American Journal of Applied Sciences 2020, Volume 17: 36.49 DOI: 10.3844/ajassp.2020.36.49

average, collected at the five AQMSs in Kuwait. It another AQMS not simply in the magnitude of the clearly shows the huge variation from one AQMS to pollution concentration but also in duration.

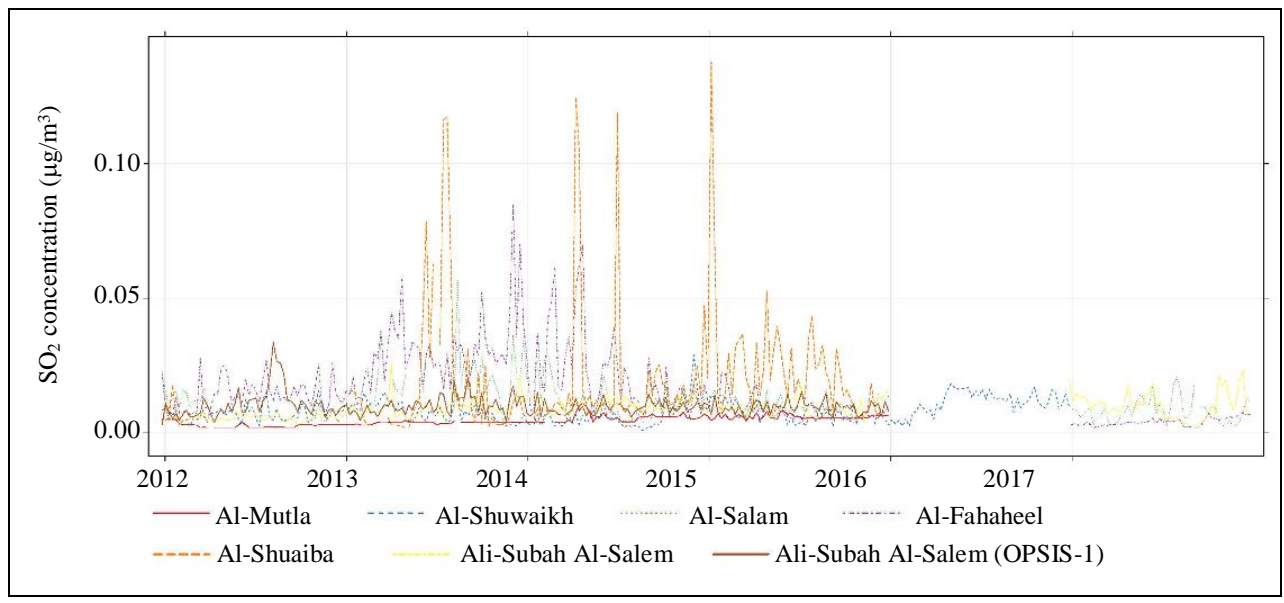

Fig. 2: Daily mean $\mathrm{SO}_{2}$

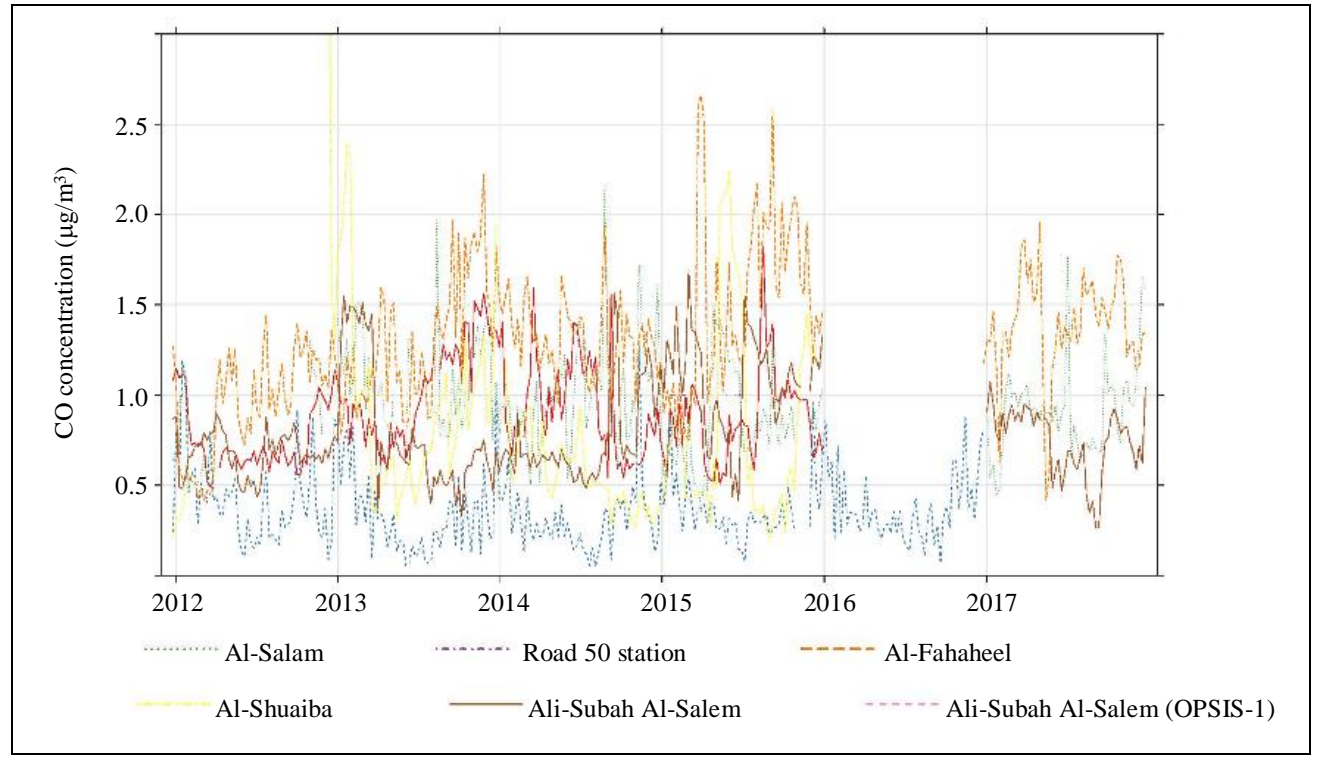

Fig. 3: Daily mean CO

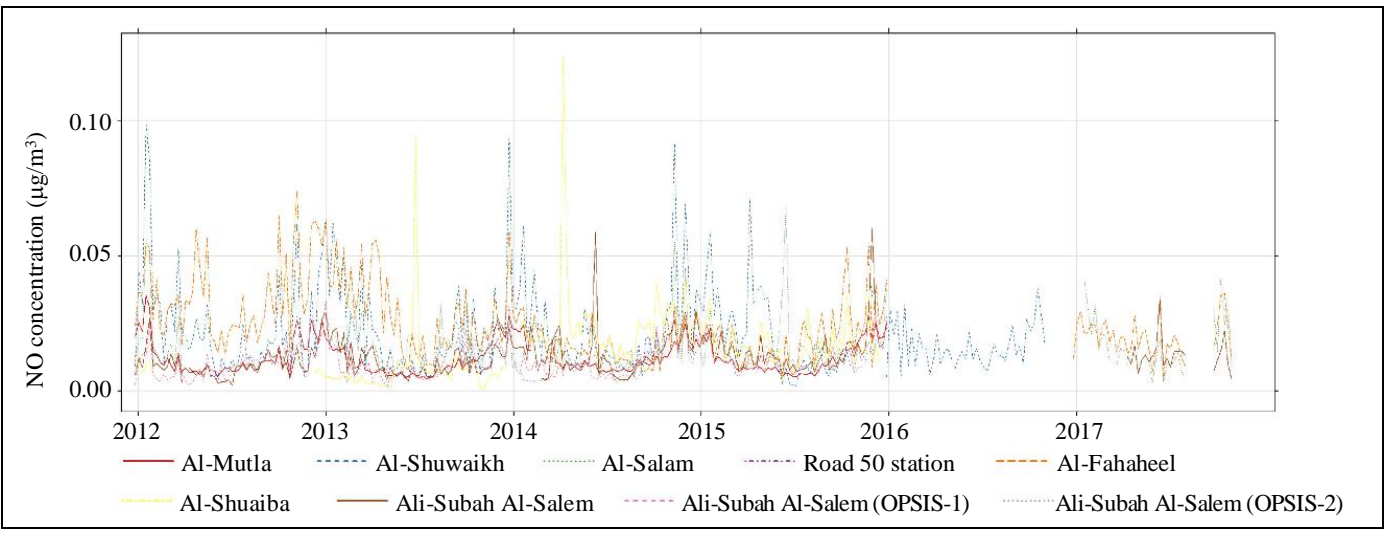

Fig. 4: Daily mean NO 


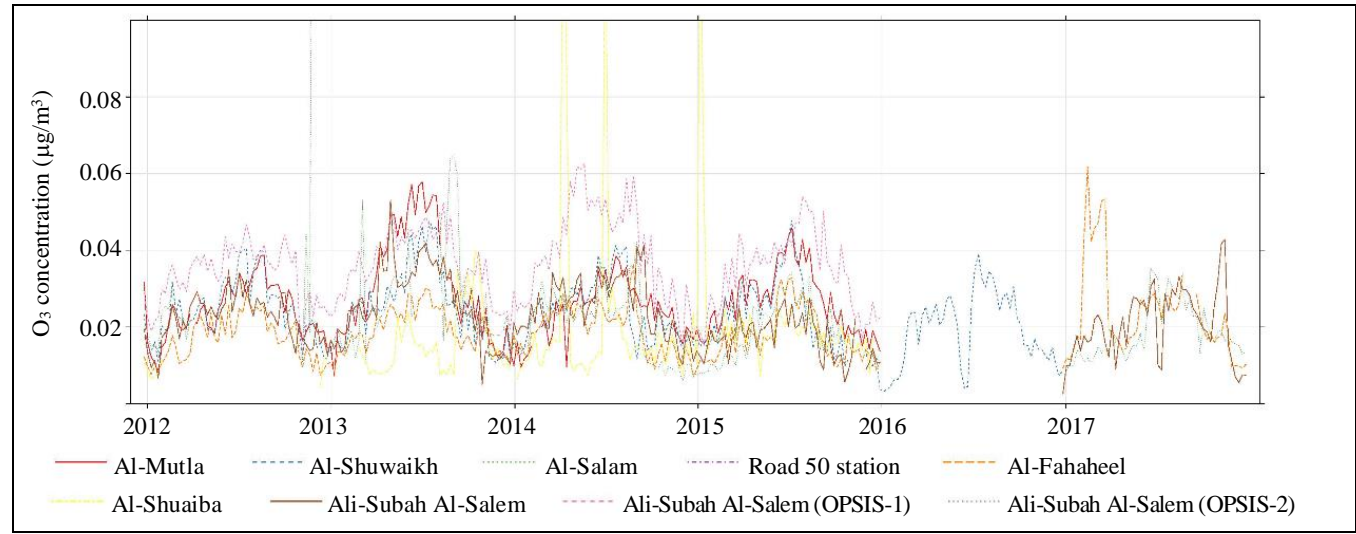

Fig. 5: Daily mean $\mathrm{O}_{3}$

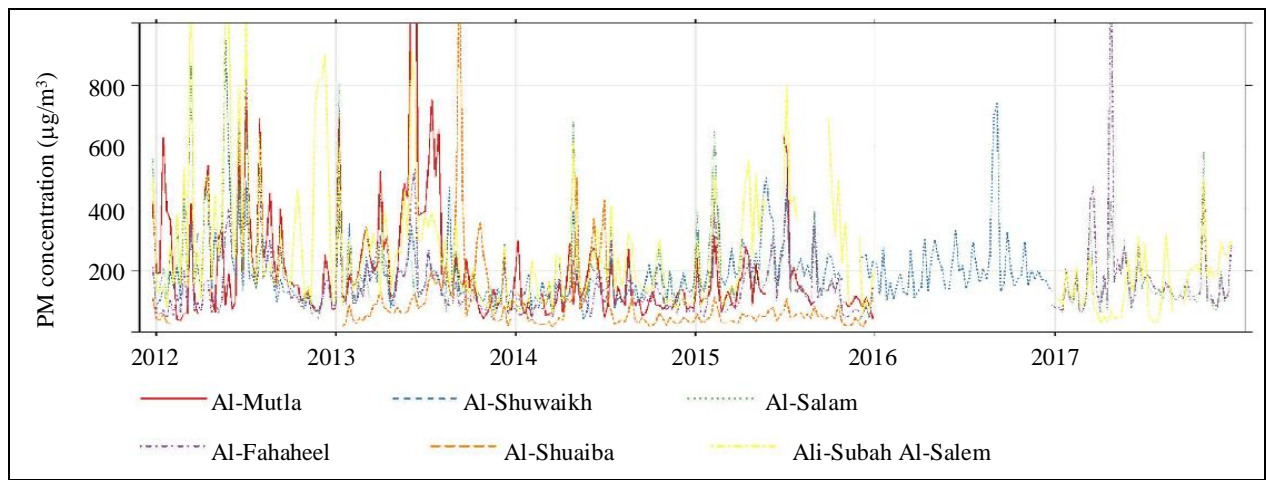

Fig. 6: Daily mean $\mathrm{O}_{3}$

Figure 7 presents the descriptive statistics of the measured concentrations of $\mathrm{SO}_{2}, \mathrm{CO}, \mathrm{O}_{3}, \mathrm{NO}$ and $\mathrm{PM}_{10}$. The mean concentrations of $\mathrm{SO}_{2}$ Al-Mutla, AlShuwaikh, Al-Salam, Al-Fahaheel, Al-Shuaiba, AliSubah Al-Salem, Ali-Subah Al-Salem (OPSIS-1) and AliSubah Al-Salem (OPSIS-2) sites were 0.00459, 0.00824, $0.01150,0.01582,0.02043,0.00911,0.01001$ and 0.00971 ppm and the minimum (and maximum) concentrations were 0.00088 (0.201), 0.00007 (0.2895), 0.0001 (0.513), 0 (0.759), 0.001 (1.619), 0 (0.394), 0.00002 (0.21223) and $0.00001(0.2768) \mathrm{ppm}$ respectively. $\mathrm{CO}$ averages for AlMutla, Al-Shuwaikh, Al-Salam, Road 50 Station, AlFahaheel, Al-Shuaiba and Ali-Subah Al-Salem sites were $0.897,0.36257,0.95140,1.09547,1.29743,0.76351$ and $0.78323 \mathrm{ppm}$ and the concentrations varied between 0.00038 and $5.85 \mathrm{ppm}, 0.01$ and $8.59873 \mathrm{ppm}, 0.00001$ and $26.35985 \mathrm{ppm}, 0.00051$ and $123.59133 \mathrm{ppm} 0.02$ and $46.29 \mathrm{ppm}, 0.01$ and $29.26 \mathrm{ppm}$ and 0.00001 and 14.57000 ppm respectively. The minimum (and maximum) NO concentrations for Al-Mutla, AlShuwaikh, Al-Salam, Road 50 Station, Al-Fahaheel, AlShuaiba, Ali-Subah Al-Salem, Ali-Subah Al-Salem (OPSIS-1) and Ali-Subah Al-Salem (OPSIS-2) sites were 0.00001 (0.7175), 0.00011 (0.588), 0.00001 (0.532), 0.00001 (0.705), 0.00067 (0.882), 0.00010 (2.28386), $0.00001 \quad(0.301), 0.00020(0.90434)$ and 0.00002
(1.59145) $\mathrm{ppm}$ and the means were $0.01227,0.02165$, $0.01495,0.07808,0.02466,0.01573,0.01257,0.01086$ and 0.01192 ppm respectively. Al-Mutla, Al-Shuwaikh, Al-Salam, Al-Fahaheel, Al-Shuaiba, Ali-Subah AlSalem, Ali-Subah Al-Salem (OPSIS-1) and Ali-Subah Al-Salem (OPSIS-2) $\mathrm{O}_{3}$ concentrations varied between $\mathrm{d}$ 0.00008 and 0.163 ppm, 0 and 0.218 ppm, 0 and 5.187 ppm, 0.001 and $0.141 \mathrm{ppm}, 0.001$ and $0.824 \mathrm{ppm}, 0$ and $0.313 \mathrm{ppm}, 0.00001$ and $0.19893 \mathrm{ppm}$ and 0.00001 and 0.1396 ppm respectively. $\mathrm{PM}_{10}$ levels Al-Mutla, AlShuwaikh, Al-Salam, Al-Fahaheel, Al-Shuaiba and AliSubah Al-Salem sites varied between 0 and $6685 \mu \mathrm{g} / \mathrm{m}^{3}$, 2 and $5131 \mu \mathrm{g} / \mathrm{m}^{3}, 0.34$ and $12429 \mu \mathrm{g} / \mathrm{m}^{3}, \quad 0$ and $20929.09 \mu \mathrm{g} / \mathrm{m}^{3}, 0.9$ and $7185 \mu \mathrm{g} / \mathrm{m}^{3}$ and 0 and 9501 $\mu \mathrm{g} / \mathrm{m}^{3}$ and the averages were 189.05, 194.81, 168.94, $153.27,83.64$ and $244.18 \mu \mathrm{g} / \mathrm{m}^{3}$ respectively.

Box plots of the data were produced and presented for the $\mathrm{CO}, \mathrm{O}_{3}, \mathrm{NO}, \mathrm{SO}_{2}$ and $\mathrm{PM}_{10}$ in Fig. 8 to 12 respectively. It is clear that the data are not normally distributed. Therefore, the data medians of eight sites were compared to the data median of the background site by using Mann-Whitney test. The data collected at eight sites, except NO data at Al-Shuwaikh site and PM data at Al-Fahaheel site, were significantly different at the 95 $\%$ confidence level to the data collected at Al-Mutla site the background. 
Hamad B Matar et al. / American Journal of Applied Sciences 2020, Volume 17: 36.49 DOI: 10.3844/ajassp.2020.36.49

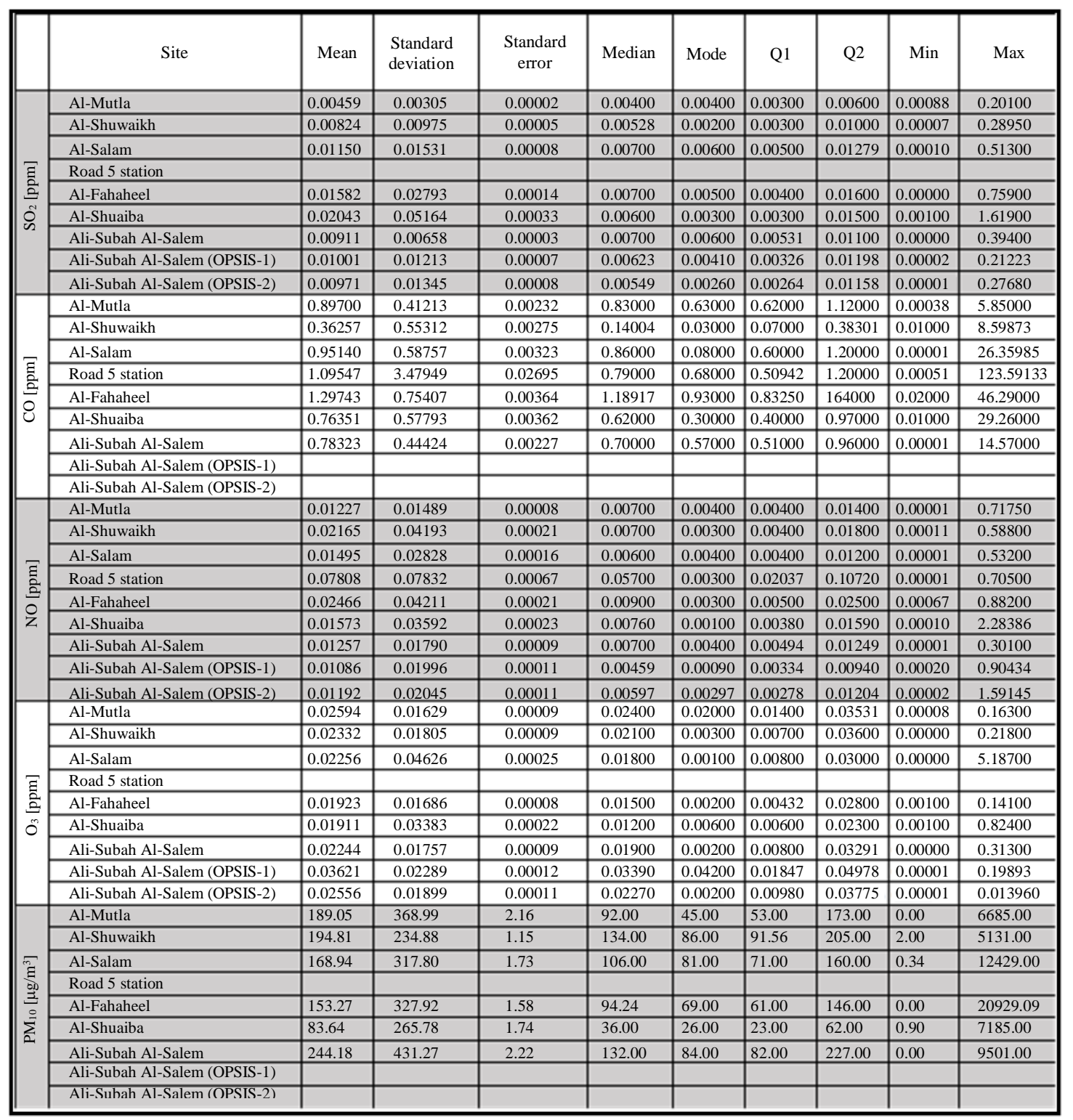

Fig. 7: The mean concentration of pollutants

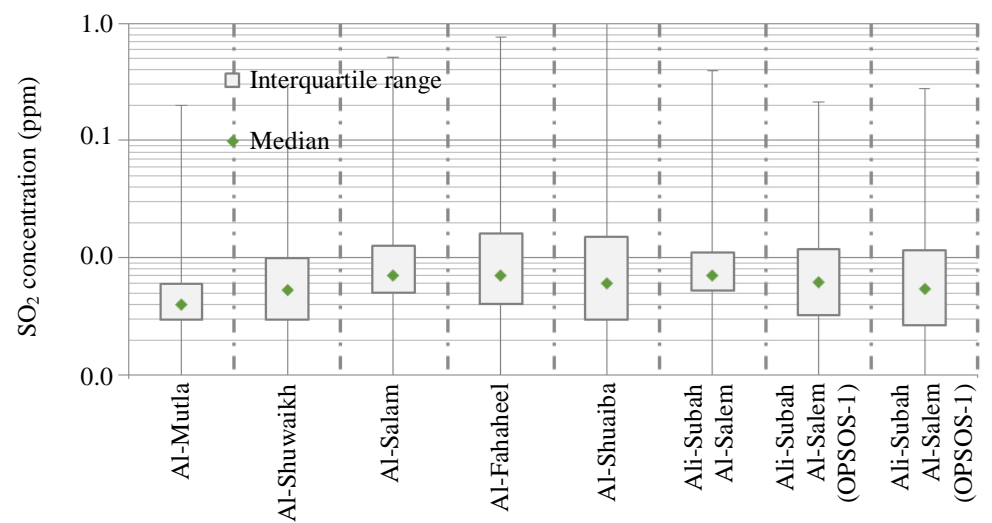

Fig. 8: Boxplot of $\mathrm{SO}_{2}$ 
Hamad B Matar et al. / American Journal of Applied Sciences 2020, Volume 17: 36.49 DOI: 10.3844/ajassp.2020.36.49

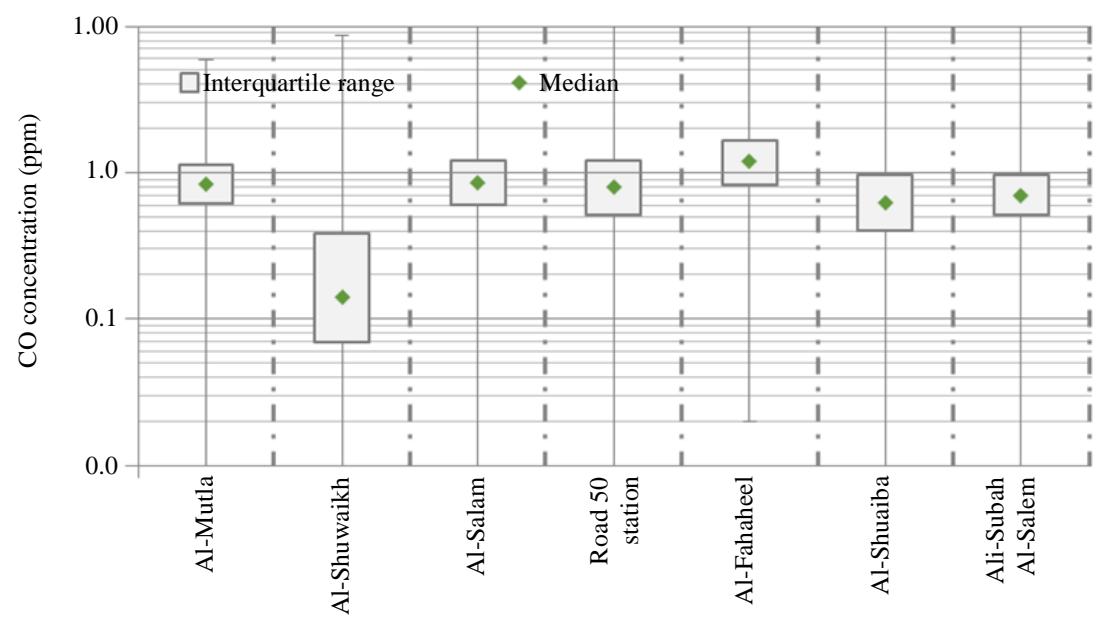

Fig. 9: Boxplot of $\mathrm{CO}$

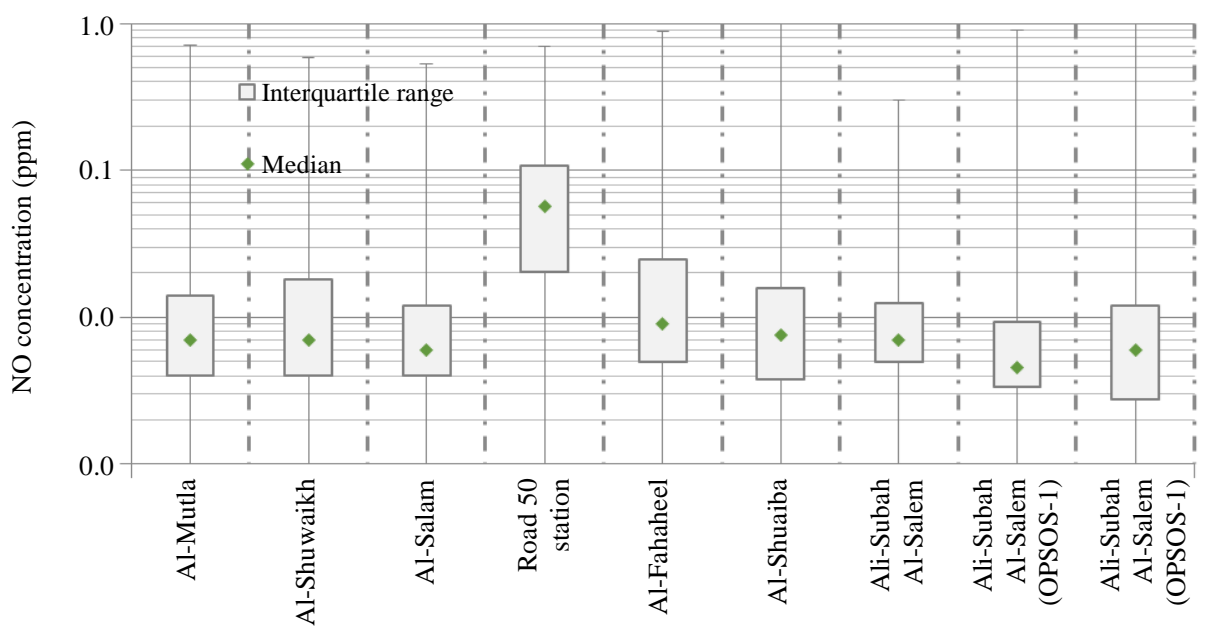

Fig. 10: Boxplot of NO

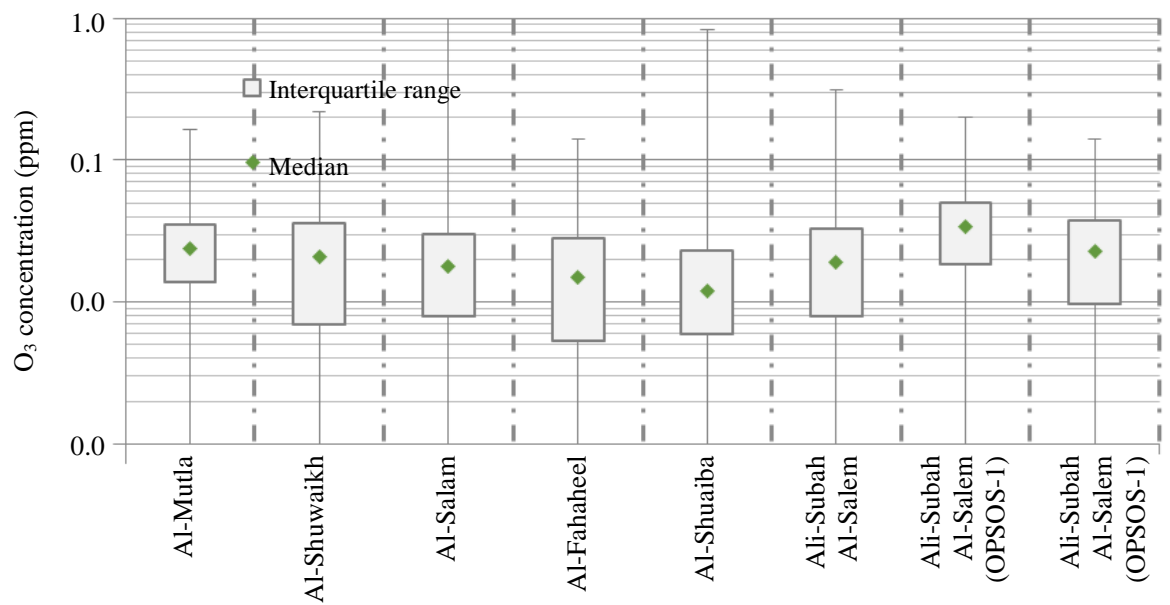

Fig. 11: Boxplot of $\mathrm{O}_{3}$ 


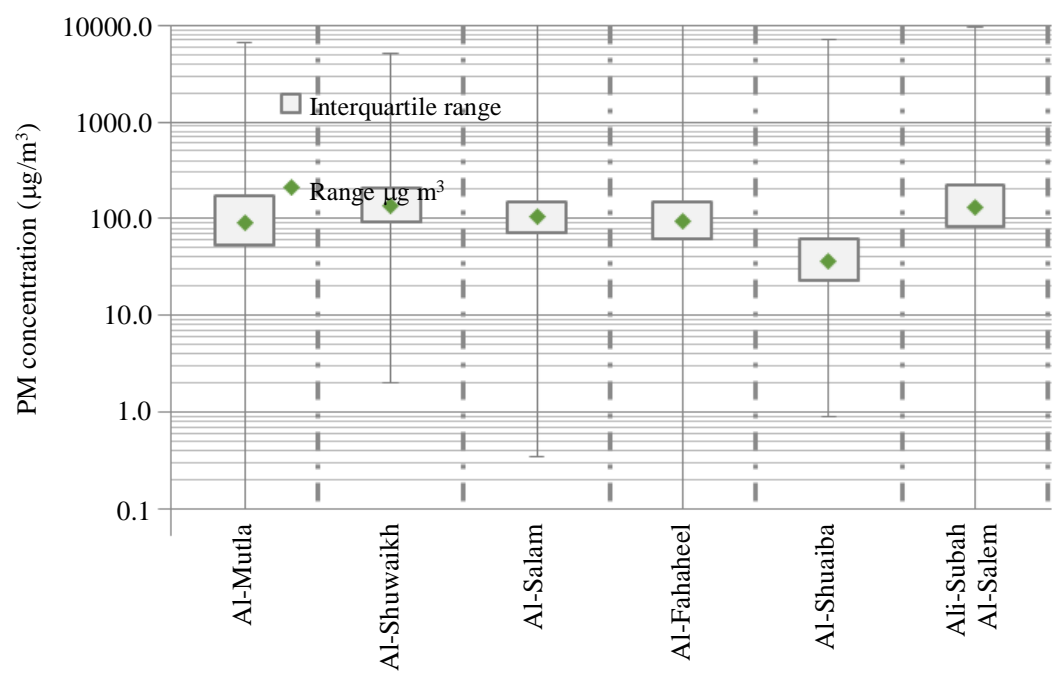

Fig. 12: Boxplot of PM

\section{Discussion}

The outdoor air quality was evaluated by obtaining selected pollutants, namely, $\mathrm{CO}, \mathrm{O}_{3}, \mathrm{NO}, \mathrm{SO}_{2}$ and $\mathrm{PM}_{10}$, it was achieved by using data obtained from five KUEPA fixed monitoring stations. Then the data used to plot the daily profile for each pollutant (Fig. 13, 15, 17, 19 and 21) to show the temper and spatial variation of air pollution. The data from nine stations were was plotted for each pollutant for comparison.

\section{Sulfur Dioxide $\left(\mathrm{SO}_{2}\right)$}

The daily profile of $\mathrm{SO}_{2}$ has either one peak or two peaks between 9:00 to 18:00 except the background site (Al-Mutla). One peak occurred between 12:00 and 18:00 at Al-Shuaiba site which is an industry area. Al-Fahaheel site which is located near the refinery, has two peaks during the daytime. Al-Salam located in an urban area, has one peak during the daytime and the rush hour. Also, Ali-Subah Al-Salem (OPSIS-1) site located near industrial and refinery areas, has one peak during the daytime. Therefore, the $\mathrm{SO}_{2}$ levels could be associated with either road traffic (Al-Salam site) or conditions related to industry and refinery (Al-Fahaheel, Al-Shuaiba and, AliSubah Al-Salem (OPSIS-1) sites), as the background did not show a similar peak to other sites. Al-Salam showed a higher level of $\mathrm{SO}_{2}$ as illustrated in Fig. 13. Figure 14 shows the wind rose with respect to the $\mathrm{SO}_{2}$ level at each site. Figure 14 shows that there are specific sources of pollution at Al-Shuwaikh, Al-Salam, Al-Fahaheel, AlShuaiba and Ali-Subah Al-Salem (OPSIS-1) sites as the $\mathrm{SO}_{2}$ levels varied with wind direction and wind speed. The Al-Shuwaikh site indicated a distant source as a high pollutant level occurred during high wind speed from North west and south east. High pollutant levels occurred during wind blown from the south and south east at Al-Salam site which means that the source was located south of the station. High pollution levels occurred at Al-Fahaheel site during high wind blowing from west and south west which indicates a distant source. However, a close source located south of the site was indicated by high pollution levels when the wind blow from the south. The Al-Shuaiba site had local and distant pollution sources from northwest indicated by high pollution level during calm wind and wind blown from north west. So wind blown showed a distant source of high pollutant level occurred during high wind speed from Northwest and south east. Short high pollutant level occurred during wind blown from a different direction at Ali-Subah Al-Salem (OPSIS-1) site. The other two sites did not show any dominant pollution source (Fig. 14). The daily profile of $\mathrm{SO}_{2}$ showed a similar variation in the pattern of peak during the daytime between sites except in the background site. The Morning peak follows the daily traffic flow at one site. There is pollutant source of $\mathrm{SO}_{2}$ at two sites shown in the wind rise plots. The background was lower than urban areas which is not consistent with findings in Ettouney et al. (2010; Alenezi and Al-Anezi, 2015).

\section{Carbon Monoxide (CO)}

The daily profile of $\mathrm{CO}$ has a systemic variation pattern as shown in Fig. 15. It has two peaks at 9:00 am and 9:00 pm. The morning peak occurred during morning rush hour. Therefore, the $\mathrm{CO}$ levels could not be associated with road traffic as the $\mathrm{CO}$ level at background shows similar peaks as the other sites located far from urban, industrial and refinery areas. The Al-Shuwaikh CO profile has lower than other sites and it shows a similar variation. 
Hamad B Matar et al. / American Journal of Applied Sciences 2020, Volume 17: 36.49 DOI: 10.3844/ajassp.2020.36.49

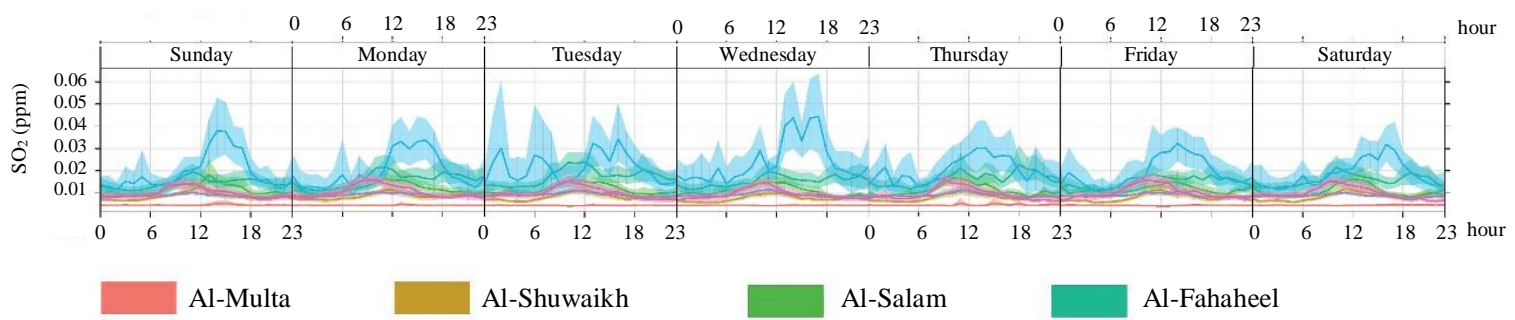

Ali-Subah Al-Salem

Ali-Subah Al-Salem (OPSIS-1)
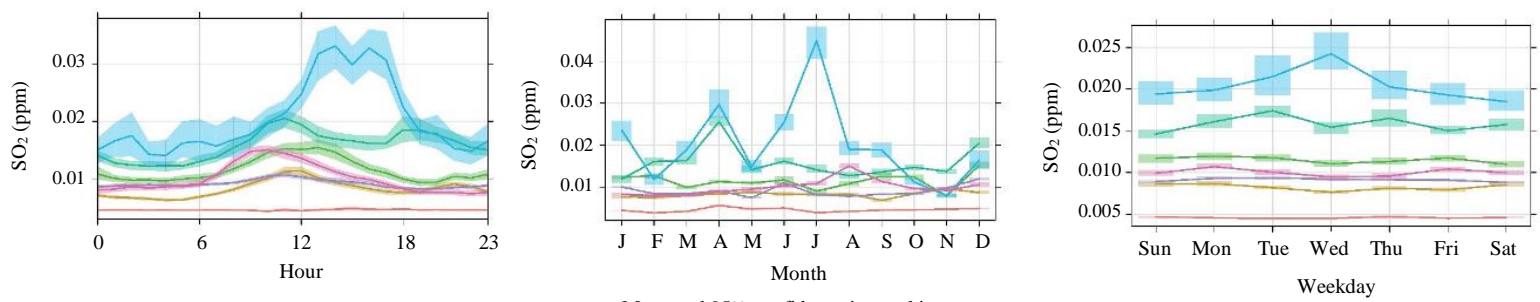

Mean and 95\% confidence interval in mean

Fig. 13: Daily profile of $\mathrm{SO}_{2}$

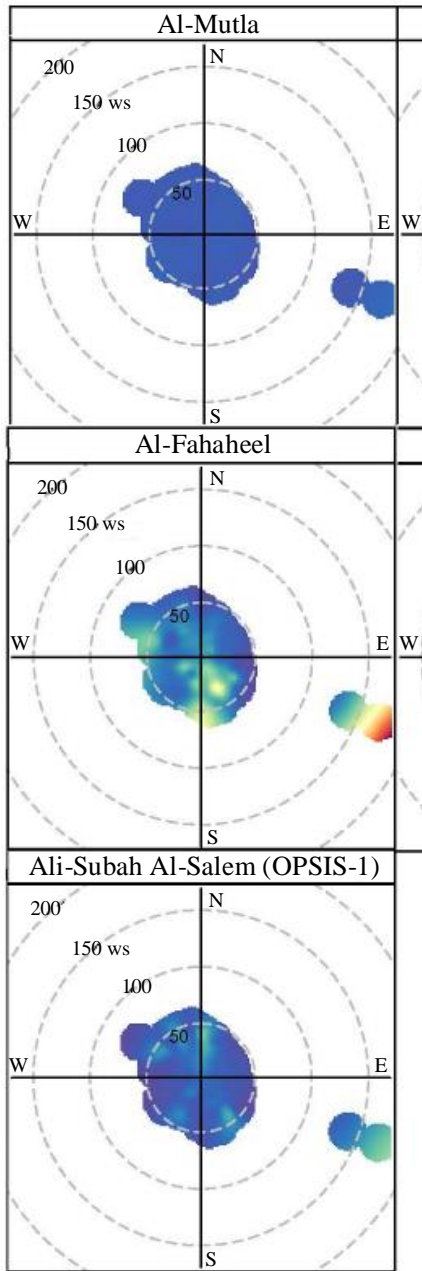

$\mathrm{SO}_{2}(\mathrm{ppm})$

$-0.14$

Fig. 14: Wind rose and $\mathrm{SO}_{2}$ level 

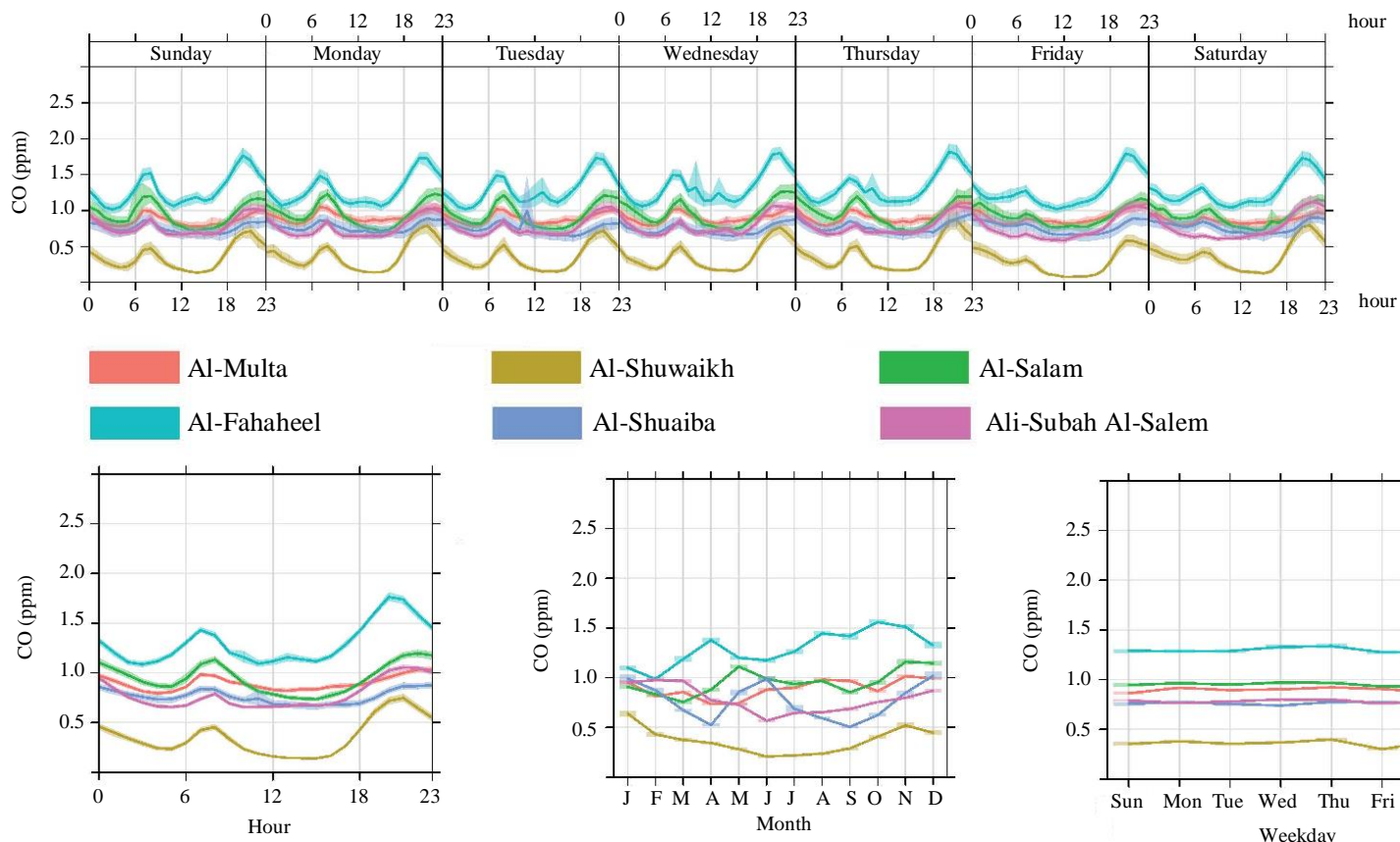
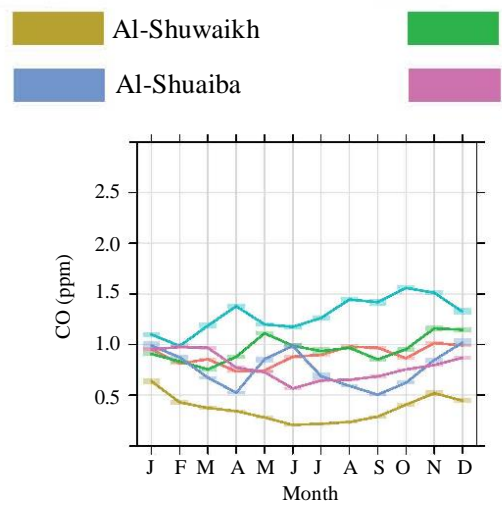

Mean and $95 \%$ confidence interval in mean
Al-Salam

Ali-Subah Al-Salem

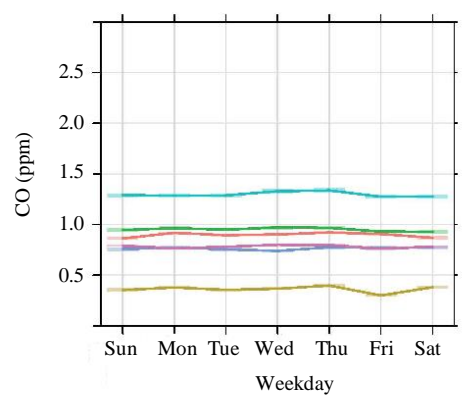

Fig. 15: Daily profile of CO
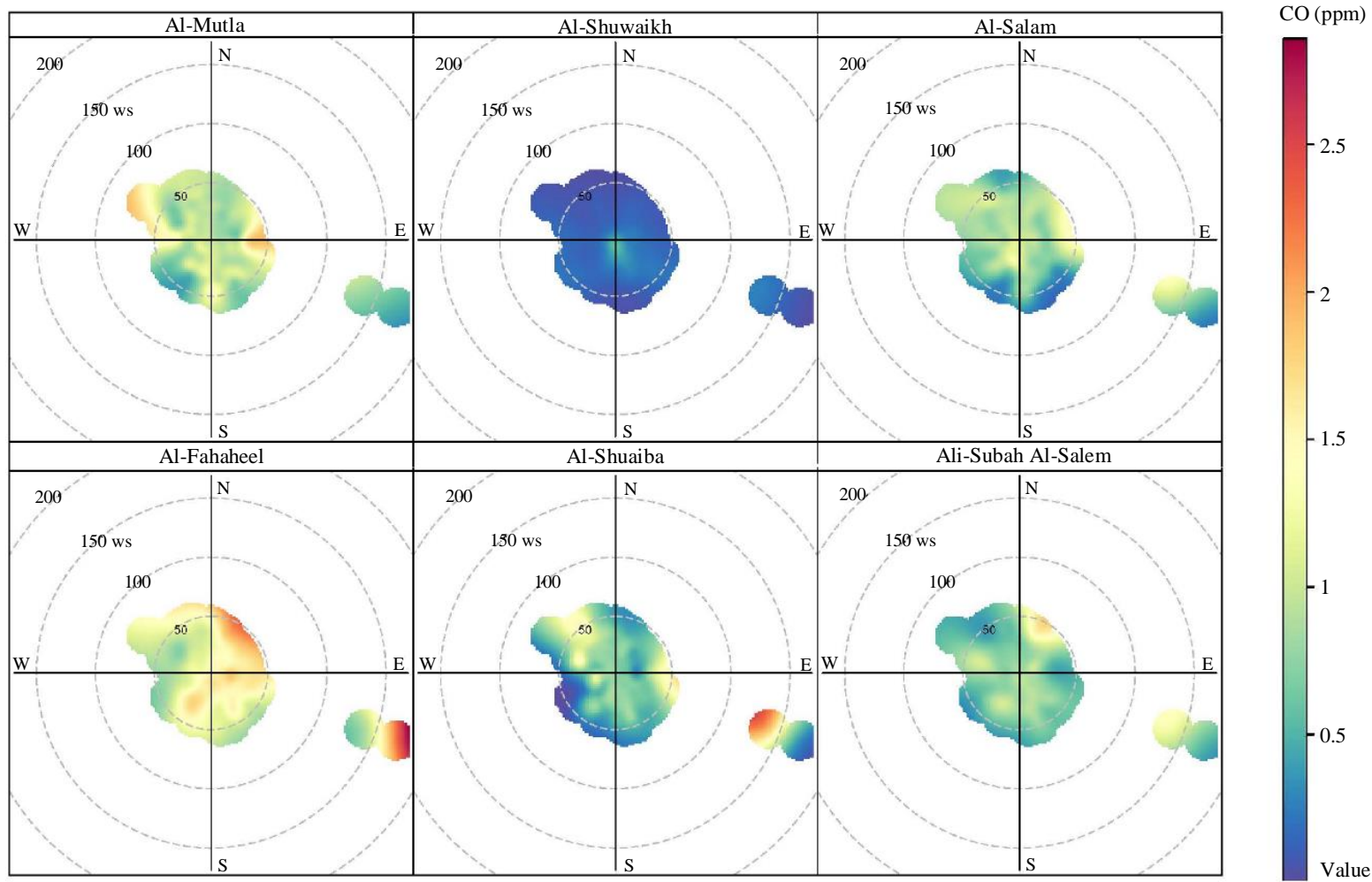

Fig. 16: Wind rose and COlevel

Figure 16 shows the wind rose in respect to $\mathrm{CO}$ level at each site. Figure 16 shows no specific source of pollution at Al-Mutla as the $\mathrm{CO}$ level were similar in all directions and wind speed. The Al-Shuwaikh shows a local source of a high pollutant level during low wind speed. High CO level correlated with high wind from 
east and north east at AL-Salam and Al-Shuaiba sites suggest a source at that direction. Also, Al-Fahaheel site shows similar CO level at all direction and wind speed, thus no specific sources of pollution. The Ali-Subah AlSalem site shows a high level of $\mathrm{CO}$ associated with wind coming from north east. It suggests the source is located far from the site and high wind speed influences the $\mathrm{CO}$ level. The daily profile of $\mathrm{CO}$ shows similar variation pattern between sites. It did not follow daily traffic flow as it did not have an afternoon peak. The CO wind rose plots show either a local or far pollutant source. This study did not have similar finding as other studies Alenezi and Al-Anezi (2015). Alenezi and AlAnezi (2015) stated that "the population density, reflected by the traffic intensity, urban construction, road layout and meteorological conditions all contribute to $\mathrm{CO}$ variation and behavior". The $\mathrm{CO}$ concentration did not exceed the KU-EPA limit of 30 ppm hourly mean and 8 ppm daily mean.

\section{Nitric Oxide (NO)}

The daily profile of NO has a systemic variation pattern. It has two peaks at 8:00 am and 9:00 pm. The morning peak occurred during the rush hour. Therefore, the NO levels could be associated with road traffic but the background site, which is located far from urban, industry and refinery areas, shows a similar level to other sites. Due to photochemical, the NO level shows a decrease during daytime (Seinfeld and Pandis, 2006). The AlFahaheel site shows higher level of NO as shown in Fig. 17. Figure 18 shows the wind rose with respected to NO level at each site. Figure 18 shows that there are specific sources of pollution at Al-Shuwaikh and Al-Fahaheel sites as the NO level varied with wind direction and wind speed. The Al-Shuwaikh shows a distant or source located to the east by high pollutant levels occurring in high wind speed. The high pollutant levels occurred when wind blew from the southeast at the Al-Fahaheel site which means that the source was located southeast of the site. The other sites did not show any dominant pollution source; as indicated in Fig. 18. The daily profile of NO showed a similar variation pattern between sites. The morning peak follows the daily traffic flow. The NO wind rose plots show a pollutant source at two sites.

\section{Ozone $\left(\mathrm{O}_{3}\right)$}

The daily profile of $\mathrm{O} 3$ has one high peak with longer period from 10:00 am to 6:00 pm. The Ali-Subah AlSalem site shows higher level of $\mathrm{O}_{3}$ as seen in Fig. 19. It occurred during the daytime and the rush hour. Due to photochemical presence, the NO level shows a increase during the daytime (Seinfeld and Pandis, 2006). Therefore, the $\mathrm{O}_{3}$ levels could be associated with road traffic but the background shows similar peak to other sites. The Al-Mutla profile shows similar level of $\mathrm{O}_{3}$ as illustrated in Fig. 19. The $\mathrm{O}_{3}$ level at each site were plotted on the wind rose as seen in Fig. 20. Figure 20 showed specific sources of pollution at all sites as the $\mathrm{O}_{3}$ level varied with wind direction and wind speed. The high pollutant levels occurred during wind blow from northwest and southeast in general. This means the source of pollutant is not local. The Ali-Subah Al-Salem (OPSIS-1) site shows a local source of high pollutant levels during low wind speed. The daily profile of $\mathrm{O}_{3}$ shows similar variation pattern between sites. The morning peak during the daytime could be linked to traffic emission. There is local pollutant source of $\mathrm{O}_{3}$ as all sites shown in the wind rose plots. The data show that $\mathrm{O}_{3}$ concentrations increase during daytime due to photochemical (Seinfeld and Pandis, 2006). Bell et al. (2004; Abdul-Wahab, 2009) present similar results.
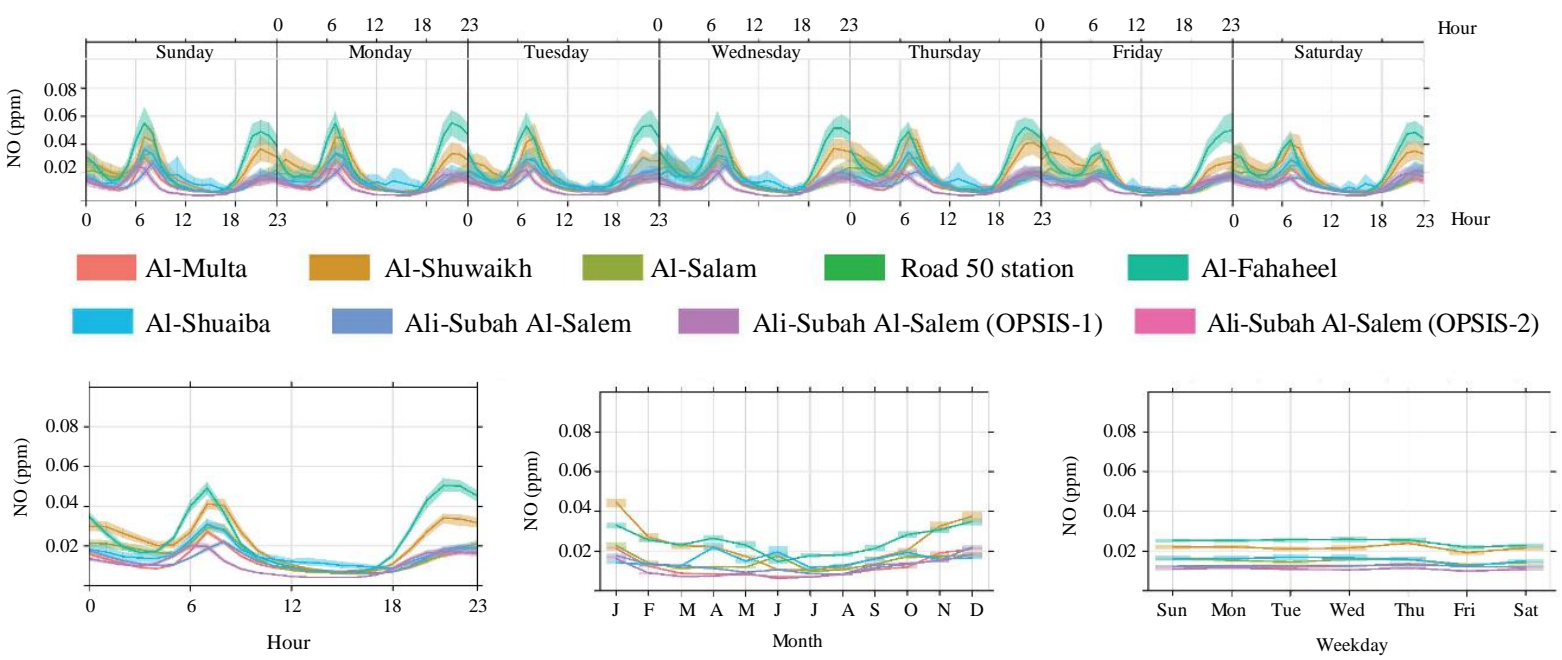

Mean and 95\% confidence interval in mean

Fig. 17: Daily profile of NO 


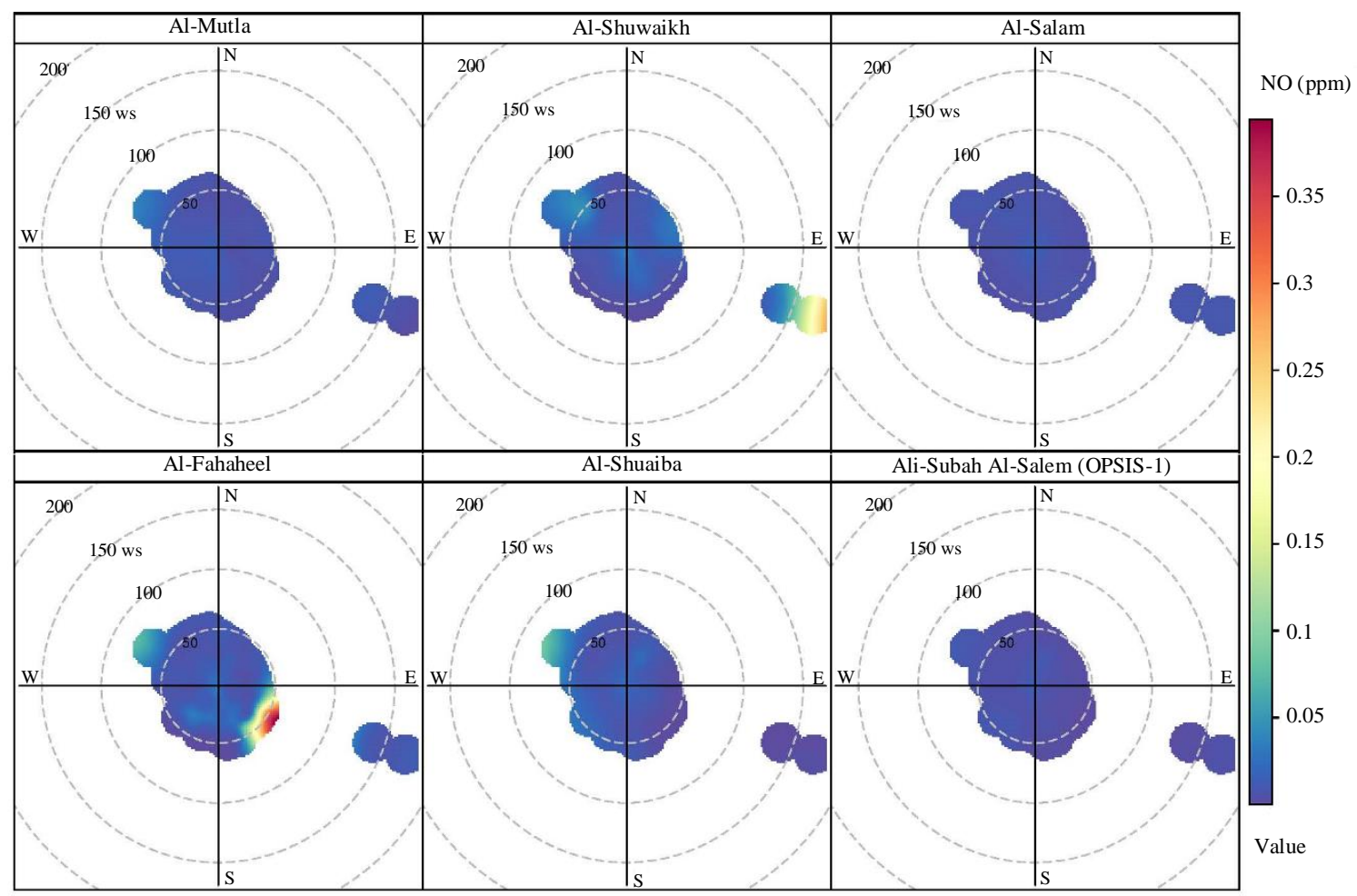

Fig. 18: Wind rose and NO level

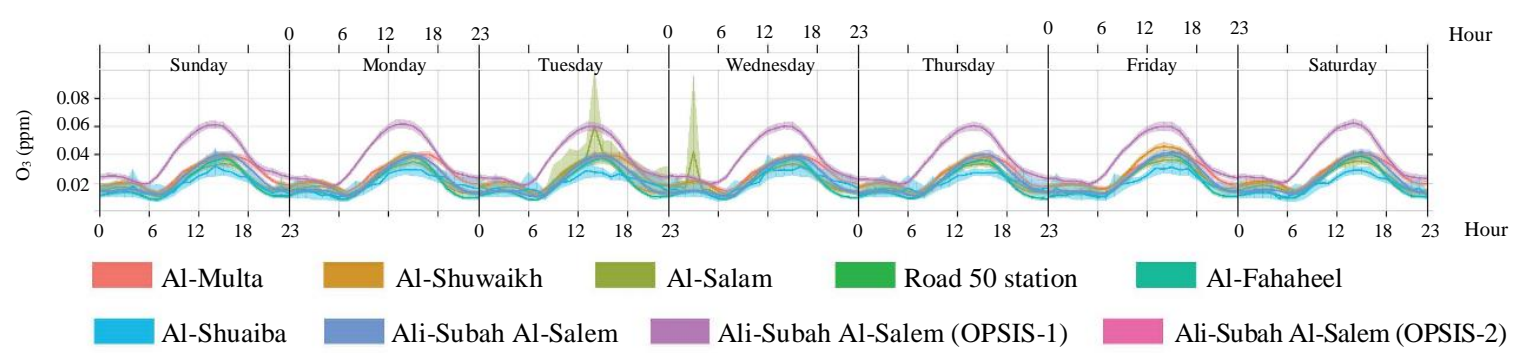

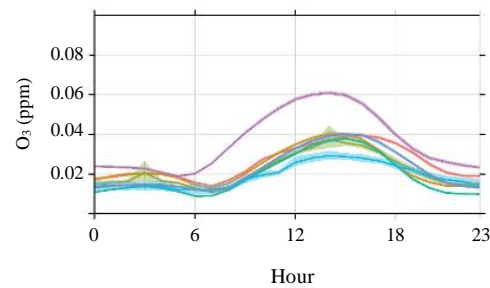

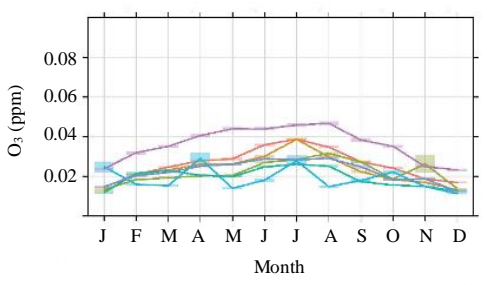

Mean and $95 \%$ confidence interval in mean

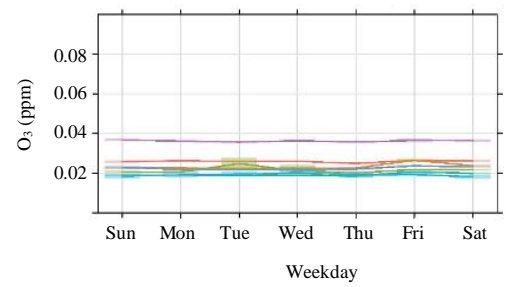

Fig. 19: Daily profile of $\mathrm{O}_{3}$

\section{Particulate Matters (PM)}

The daily profile of PM at the Al-Mutla and Ali-Subah Al-Salem sites have one peak with a longer daytime period from 08:00 am to 4:00 pm, Fig. 21. It occurred during the daytime and the rush hour. Therefore, the PM levels could be associated with road traffic but the background shows a similar peak to the other site. Boogaard et al. (2011) stated that PM was related to traffic. The daily profile of PM at the Al-Shuaiba site shows lower values compare to the other sites. The PM level at each site were plotted on the wind rose as shown in Fig. 22. Figure 22 shows that there are specific sources of pollution at five sites as the PM level varied with high wind from north and south in general. This means the source of pollutant is far from these sites. The daily profile of PM shows a similar variation pattern 
Hamad B Matar et al. / American Journal of Applied Sciences 2020, Volume 17: 36.49 DOI: 10.3844/ajassp.2020.36.49

between the two sites. The morning peak during the daytime could not be linked to traffic emission. There is a distant pollutant source of PM in the five sites as shown in the wind rose plots.

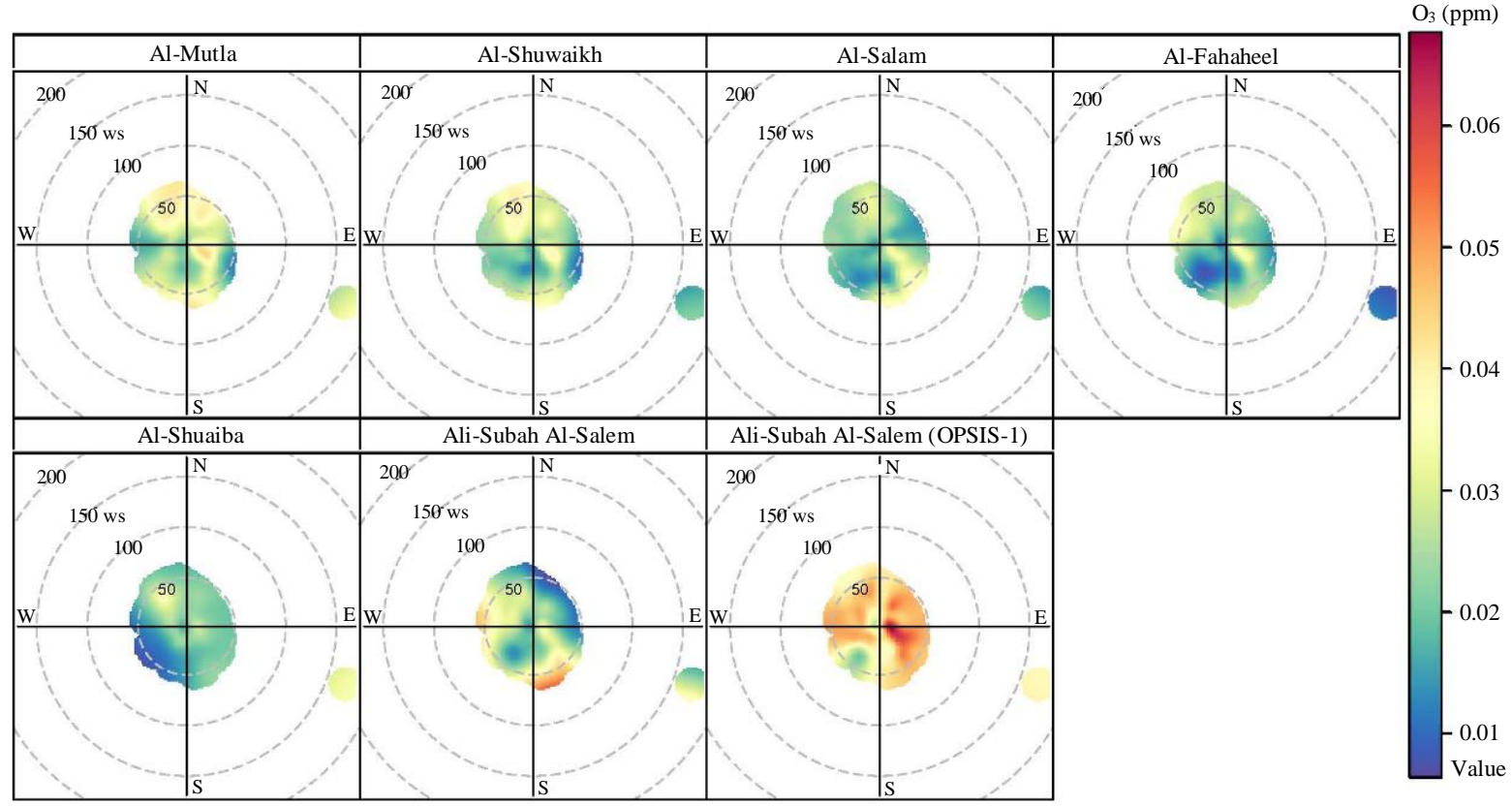

Fig. 20: Wind rose and $\mathrm{O}_{3}$ level

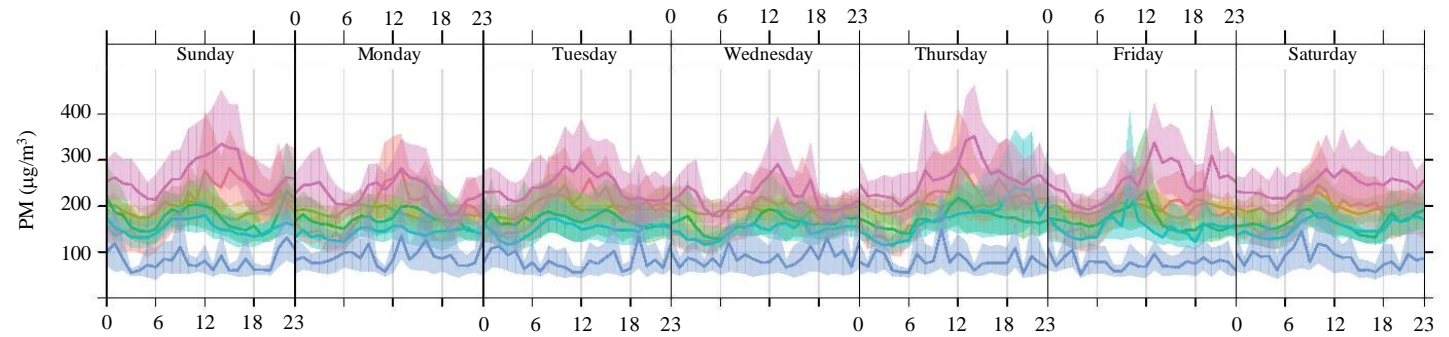

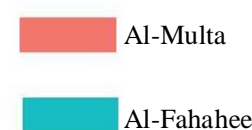

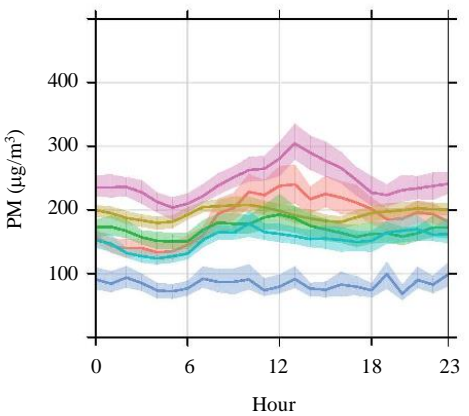

Al-Shuwaikh

Al-Shuaiba

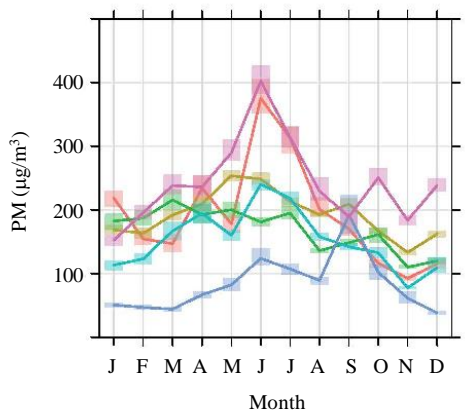

Mean and $95 \%$ confidence interval in mean

Al-Salam

Ali-Subah Al-Salem

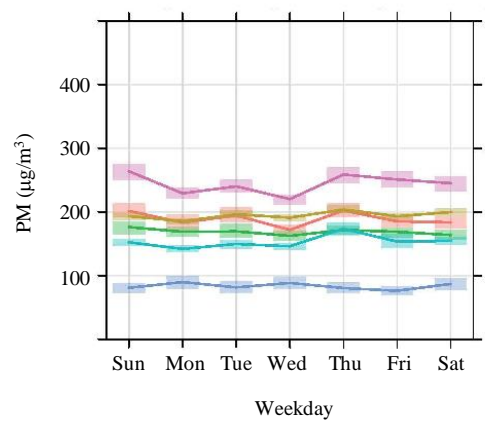

Fig. 21: Daily profile of PM 


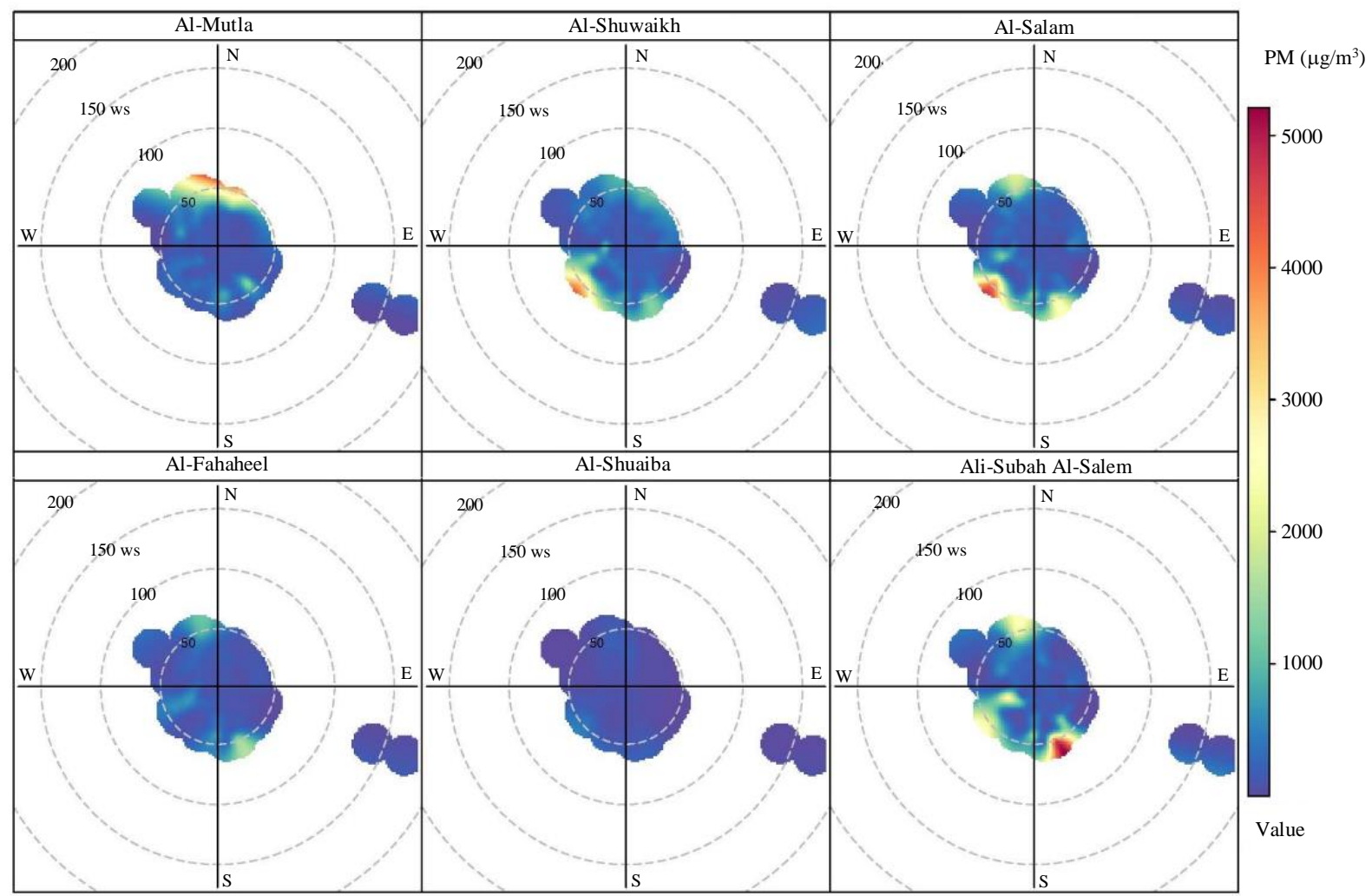

Fig. 22: Wind rose and PM level

\section{Conclusion and Recommendations}

The outdoor levels of $\mathrm{CO}, \mathrm{O}_{3}, \mathrm{NO}, \mathrm{SO}_{2}$ and PM10 were evaluated. The data was obtained from five KUEPA fixed monitoring stations. The data was used to plot the daily profile to show the temper and spatial variation of the air pollution. The daily profile of $\mathrm{SO}_{2}$ at the background shows a different variation pattern to the other sites and the daily profile of PM at the sites shows similar variation pattern. $\mathrm{CO}, \mathrm{O}_{3}$ and $\mathrm{NO}$ daily patterns show a similar pattern among each pollutant. $\mathrm{SO}_{2}, \mathrm{O}_{3}$, $\mathrm{NO}$ and PM peak could not be linked to traffic. The wind rose plot was used to identify either a local or distant pollution source.

\section{Acknowledgment}

The authors want to thanks KU-EPA for providing air pollution and metrological data.

\section{Author's Contributions}

Hamad B Matar: Writing the paper and analysis.

Talal Almutairi: Literation review, data collection and preparation.

Nayef Z. Al-Mutairi: Editing and prepare for publication.

\section{Ethics}

This article is original and contains unpublished material. The corresponding author confirms that all of the other authors have read and approved the manuscript and no ethical issues involved.

\section{References}

Abbey, D.E., N. Nishino, W.F. McDonnell, R.J. Burchette and S.F. Knutsen et al., 1999. Long-term inhalable particles and other air pollutants related to mortality in nonsmokers. Am. J. Respiratory Critical Care Med., 159: 373-382. PMID: 9927346

Abdul-Wahab, S.A., 2009. Two case studies of air pollution from Oman and Kuwait. Int. J. Environ. Stud., 66: 179-191.

Al-Awadhi, J.M., 2014. Measurement of air pollution in Kuwait City using passive samplers. Atmos. Climate Sci., 4: 253-271. DOI: $10.4236 /$ acs.2014.42028

Al-Khulaifi, N.M., H.F. Al-Mudhaf, R. Alenezi, A.S.I. Abu-Shady and M.I. Selim, 2014. Seasonal and temporal variations in volatile organic compounds in indoor and outdoor air in Al-Jahra City, Kuwait. J. Environ. Protect., 5: 310-326. DOI: $10.4236 /$ jep.2014.54034 
Al-Mutairi, N. and P. Koushki, 2009. Potential contribution of traffic to air pollution in the State of Kuwait. Am. J. Environ. Sci., 5: 218-222.

DOI: 10.3844/ajessp.2009.218.222

Al-Rashidi, M.S., V. Nassehi and R.J. Wakeman, 2005. Investigation of the efficiency of existing air pollution monitoring sites in the state of Kuwait. Environ. Pollut., 138: 219-229.

DOI: 10.1016/j.envpol.2005.04.006

Al-Temeemi, A.S., 1995. Climatic design techniques for reducing cooling energy consumption in Kuwaiti houses. Energy Build., 23: 41-48.

DOI: 10.1016/0378-7788(95)00915-K

Alenezi, R.A. and B.S. Al-Anezi, 2015. An assessment of ambient air quality in two major cities in the state of Kuwait. Int. J. Eng. Technol., 4: 358-368. DOI: $10.14419 /$ ijet.v4i2.4550

Anderson, H.R., 2009. Air pollution and mortality: A history. Atmos. Environ., 43: 142-152. DOI: 10.1016/j.atmosenv.2008.09.026

Bell, M.L., A. McDermott, S.L. Zeger, J.M. Samet and F. Dominici, 2004. Ozone and short-term mortality in 95 US urban communities, 1987-2000. JAMA, 292: 2372-2378. DOI: 10.1001/jama.292.19.2372

Boogaard, H., G.P.A. Kos, E.P. Weijers, N.A.H. Janssen and P.H. Fischer et al., 2011. Contrast in air pollution components between major streets and background locations: Particulate matter mass, black carbon, elemental composition, nitrogen oxide and ultrafine particle number. Atmos. Environ., 45: 650-658.

DOI: $10.1016 /$ j.atmosenv.2010.10.033

Dockery, D.W., C.A. Pope 3rd, X. Xu, J.D. Spengler and J.H. Ware et al., 1993. An association between air pollution and mortality in six U.S. cities. New England J. Med., 329: 1753-1759.

DOI: 10.1056/NEJM199312093292401

EFDBB, 2004. Economic and financial data base for bankers. Research Unit, Kuwait.

EPA, 2006. Terms of environment: Glossary, abbreviations and acronyms. U.S. Environmental Protection Agency.

Ettouney, R.S., J.G. Zaki, M.A. El-Rifai and H.M. Ettouney, 2010. An assessment of the air pollution data from two monitoring stations in Kuwait. Toxicol. Environ. Chem., 92: 655-668.

DOI: 10.1080/02772240903008609

Lin, S., X. Liu, L.H. Le and S.A. Hwang, 2008. Chronic exposure to ambient ozone and asthma hospital admissions among children. Environ. Health Perspectives. 116: 1725-1730.

DOI: $10.1289 /$ ehp. 11184
MIK, 2019. Ministry of Interior Kuwait. General Department of Traffic Statistics Report.

Murena, F. and G. Favale, 2007. Continuous monitoring of carbon monoxide in a deep street canyon. Atmos. Environ., 41: 2620-2629.

DOI: $10.1016 /$ j.atmosenv.2006.11.017

Pope, C.A., M.J. Thun, M.M. Namboodiri, D.W. Dockery and J.S. Evans et al., 1995. Particulate air pollution as a predictor of mortality in a prospective study of U.S. Adults. Am. J. Respiratory Critical Care Med., 151: 669-674.

DOI: 10.1164/ajrccm/151.3_Pt_1.669

Seinfeld, J.H. and S.N. Pandis, 2006. Atmospheric Chemistry and Physics: From Air Pollution to Climate Change. 2nd Edn., Wiley, ISBN-10: 0471720186, pp: 1232.

U.S.EPA, 2006. Air quality criteria for ozone and related photochemical oxidants. Final Report, Washington, DC.

Vallero, D.A., 2008. Fundamentals of air Pollution. 4th Edn., Elsevier, Boston, ISBN-10: 0123736153, pp: 942.

WHO, 1987. Air quality guidelines for Europe. European No. 23. WHO Regional Publication, Copenhagen.

Yang, W. and S. Omaye, 2008. Air pollutants, oxidative stress and human health. Mutat. Res., 674: 45-54. DOI: 10.1016/j.mrgentox.2008.10.005

Zhang, K. and S. Batterman, 2013. Air pollution and health risks due to vehicle traffic. Sci. Total Environ., 450-451: 307-316.

DOI: $10.1016 /$ j.scitotenv.2013.01.074 